\title{
Intracellular redox-responsive nanocarrier for plasmid delivery: in vitro characterization and in vivo studies in mice
}

This article was published in the following Dove Press journal:

International Journal of Nanomedicine

II October 2016

Number of times this article has been viewed

\author{
Lifen Zhang ${ }^{1,2}$ \\ Yushun Zhang ${ }^{1,2}$ \\ Zhenzhen Chen ${ }^{3}$ \\ Yuling $\mathrm{He}^{\prime}$ \\ 'State Key Laboratory of Applied \\ Organic Chemistry, ${ }^{2}$ Key Laboratory \\ of Nonferrous Metals Chemistry \\ and Resources Utilization of Gansu \\ Province, College of Chemistry \\ and Chemical Engineering, Lanzhou \\ University, Lanzhou, ${ }^{3}$ Department of \\ Bioengineering, Zhengzhou University, \\ Zhengzhou, Henan, People's Republic \\ of China
}

Correspondence: Lifen Zhang State Key Laboratory of Applied Organic Chemistry, Key Laboratory of Nonferrous Metals Chemistry and Resources Utilization of Gansu Province, College of Chemistry and Chemical Engineering, Lanzhou University, Lanzhou 730000, People's Republic of China Tel +86 93। 89| 2528

Email Ifzhang@|zu.edu.cn

Zhenzhen Chen

Department of Bioengineering, Zhengzhou University, 100 Science Road, Zhengzhou 45000I, Henan, People's Republic of China Email chenzz2010@Izu.edu.cn

\begin{abstract}
Although some modifications of polyethyleneimine (PEI) properties have been explored to balance the transfection efficiency and cytotoxicity, its successful plasmid delivery in vitro and in vivo to realize its true therapeutic potentials remains a major challenge, mainly due to intracellular trafficking barriers. Herein, we present a delivery nanocarrier Pluronic-PEI-SS by conjugating reducible disulfide-linked PEI (PEI-SS) to biocompatible Pluronic for enhanced DNA delivery and transfection efficiency in vitro and in vivo. Pluronic-PEI-SS strongly condensed plasmid DNA to low positively charged nanocomplexes, exhibited good stability against deoxyribonuclease I digestion, and tended to be easily degraded in the presence of reducing agent 1,4-dithiothreitol. The in vitro transfection of the complex Pluronic-PEI-SS/DNA into HeLa and 293 T cells resulted in lower cytotoxicity as well as significantly higher cellular uptake, nucleus transfection, and gene expression than Pluronic-PEI (25 kDa), PEI-SS, and PEI $25 \mathrm{kDa}$ given alone. Furthermore, the in vivo transfection study demonstrated that Pluronic-PEI-SS/DNA complexes induced a higher enrichment than the commercial PEI/DNA complex in the tumor, indicating their potential application as biocompatible vector in gene delivery.
\end{abstract}

Keywords: responsive, gene delivery, polycation, Pluronic, disulfide-linked

\section{Introduction}

Gene therapy has gained significant attention over the past 2 decades as a promising approach for treating genetic disorders such as severe combined immunodeficiency ${ }^{1}$ and cystic fibrosis, ${ }^{2}$ as well as an alternative method to traditional chemotherapy used in treating cancer. ${ }^{2-4}$ Nucleic acids are easily degraded by enzymes within a couple of hours due to their susceptibilities to nuclease attacks. ${ }^{5}$ Therefore, it is necessary to use appropriate delivery carriers for DNA to enable enhanced translocation into cells and protection against enzyme-mediated degradation. Cationic polymer, polyethyleneimine (PEI), as a superior nonviral gene vector, ${ }^{6}$ was found to effectively condense plasmid, protect gene from degradation, transfect DNA into cells, and rupture the endosome because of its "proton sponge" nature. ${ }^{7}$ Unfortunately, there are still severe drawbacks for PEI/DNA polyplexes, such as serious cytotoxicity and poor DNA release, which reduce their transfection efficiencies and, especially, limit their potential applications in in vivo cancer therapy. ${ }^{8,9}$

In order to balance the transfection efficiency and cytotoxicity, some modifications of PEI properties were explored. Up to now, PEI has been modified with chloroquine, polyethylene glycol, heparin, folic acid, Pluronic (poly[ethylene oxide]-b-poly[propylene oxide]-b-poly[ethylene oxide]), and so on. ${ }^{10}$ For example, hydrophilic Pluronic polymers can possess the unique ability to incorporate into cell submit your manuscript Dovepress f 
membranes as a result of the presence of the hydrophobic poly(propylene oxide) chain, as well as particular efficiency for transferring DNA in vivo, and good biocompatibility. ${ }^{1-18}$ It was reported that the overall gene transfection efficiency of polyplexes formulated with Pluronic-grafted PEI (25 kDa) was far higher than those formulated with Pluronic-grafted PEI (2 kDa) and unmodified PEI (25 kDa). However, their inefficient DNA release caused their low in vitro and in vivo gene transfection efficiency due to the strong binding between PEI $25 \mathrm{kDa}$ segments and DNA. ${ }^{19}$

Therefore, in this study, novel bioreducible copolymer consisting of Pluronic and disulfide-containing low-molecularweight PEI-SS was prepared via a simple conjugation. PEI-SS was used to facilitate DNA release, which can be readily triggered by internal factors (eg, glutathione [GSH]), ${ }^{20}$ and tend to be reduced and cleaved to low-molecular-weight linear PEI chains. Then, DNA would be quickly released from the complexes due to the weak electronic interaction of PEI short chains with DNA due to the reducibility of the PEI-SS (Figure 1). We investigated the DNA binding affinities, stability, degradability dependancy on reducing agent 1,4-dithiothreitol (DTT), cytotoxicity, and especially detailed in vitro and in vivo transfection efficacy of the nanocarrier Pluronic-PEI-SS, compared to PEI-SS, PluronicPEI (25 kDa) copolymer, and commercial $25 \mathrm{kDa}$ PEI. The results demonstrated that Pluronic-PEI-SS is capable of reducing triggered DNA release and exhibits highly improved efficiency in DNA delivery both in vitro and in vivo, indicating its potential application as biocompatible vector in gene delivery.

\section{Materials and methods Materials}

Linear PEI (MW =600 Da), branched commercial PEI (MW =25 kDa), Pluronic P123, DTT, dimethyl sulfoxide (DMSO), Dulbecco's phosphate-buffered saline (PBS), cystamine dihydrochloride, 1,1'-carbonyldiimidazole, 3-(4,5-dimethylthiazol-2-yl)-2,5-diphenyltetrazolium bromide (MTT), and Dulbecco's Modified Eagle's Medium (DMEM) were all obtained from Sigma-Aldrich Co. (St Louis, MO, USA). Acryloyl chloride was obtained from Rionlon Bohua (Tianjin) Pharmaceutical and Chemical Co, Ltd. (Tianjin, People's Republic of China). Penicillinstreptomycin and fetal bovine serum (FBS) solutions were supplied from Thermo Fisher Scientific (Waltham, MA, USA). Plasmid pBR322 DNA and pGL4-control reporter gene were purchased from Fermentas China Co., Ltd. (Shenzhen, Guangdong, People's Republic of China). Plasmid enhanced green fluorescent protein (pEGFP) containing the early promoter of Cytomegalovirus and enhanced green fluorescent protein (EGFP) was kindly donated by Professor Liang (Jianghan University). pEGFP was conjugated with 2-([1E,3E,5E]-5-[1-\{5-carboxypentyl\}-3,3-dimethylindolin2-ylidene]penta-1,3-dienyl)-1-ethyl-3,3-dimethyl-3H-indolium chloride (Cy5) according to the protocol of the Label IT $^{\circledR}$ Tracker $^{\mathrm{TM}}$ intracellular nucleic acid localization kit (Mirus Bio LLC, Madison, WI, USA). Male nude mice (4-5 weeks old) were purchased from the Shanghai Experimental Animal Center (People's Republic of China). All animal experiments complied with the requirements of the National Act on the Use of Experimental Animals (People's Republic of China). This study was approved by the Medical Ethics Committee of The First Hospital of Lanzhou University.

\section{Synthesis of Pluronic-PEI-SS conjugate copolymer and Pluronic-PEl (25 kDa)}

PEI-SS was synthesized first according to conventional Schotten-Baumann conditions. ${ }^{21}$ Briefly, equimolar acryloyl chloride and cystamine were dissolved in dichloromethane at room temperature using trimethylamine as a catalyst. After the reaction was completed, cystamine bisacrylamide was obtained by filtration, purified by crystallization, and dried under vacuum. Then, the disulfide PEI-SS was synthesized through Michael addition between cystamine bisacrylamide and $600 \mathrm{Da}$ PEI. The structures of PEI-SS were confirmed by proton nuclear magnetic resonance ( $\left.{ }^{1} \mathrm{H} \mathrm{NMR}\right)$ and gel permeation chromatographymulti-angle laser light scattering (GPC-MALLS).

Pluronic-PEI-SS and Pluronic-PEI were synthesized by grafting Pluronic P123 to the amino groups of PEI-SS and PEI $25 \mathrm{kDa}$, as described previously. ${ }^{22}$ Briefly, the dissolved P123 (1.25 g) in tetrahydrofuran (THF, $15 \mathrm{~mL}$ ) was slowly added to a solution of anhydrous THF containing carbonyldiimidazole $(0.81 \mathrm{~g})$ in a dropwise manner. After the reaction was carried out for 6 hours at room temperature under nitrogen atmosphere, 1,1-carbonyldiimidazole-activated P123 was obtained by precipitating three times in ice-cold diethyl ether. Then, the activated P123 in $15 \mathrm{~mL}$ anhydrous THF was allowed to react with PEI-SS at room temperature under nitrogen atmosphere for 48 hours. The resulting Pluronic-PEI-SS conjugate copolymers were dialyzed using Spectra/Por@ Biotech Dialysis membrane (MWCO 14 kDa), lyophilized, and characterized by ${ }^{1} \mathrm{H}$ NMR and GPC-MALLS. Pluronic-PEI (25 kDa) copolymer was synthesized by the conjugation of activated P123 with PEI $(25 \mathrm{kDa})$ according to similar procedure.

\section{Degradation of Pluronic-PEI-SS}

Behavior of the copolymer Pluronic-PEI-SS degradation in the presence of DTT was investigated by GPC-MALLS, 

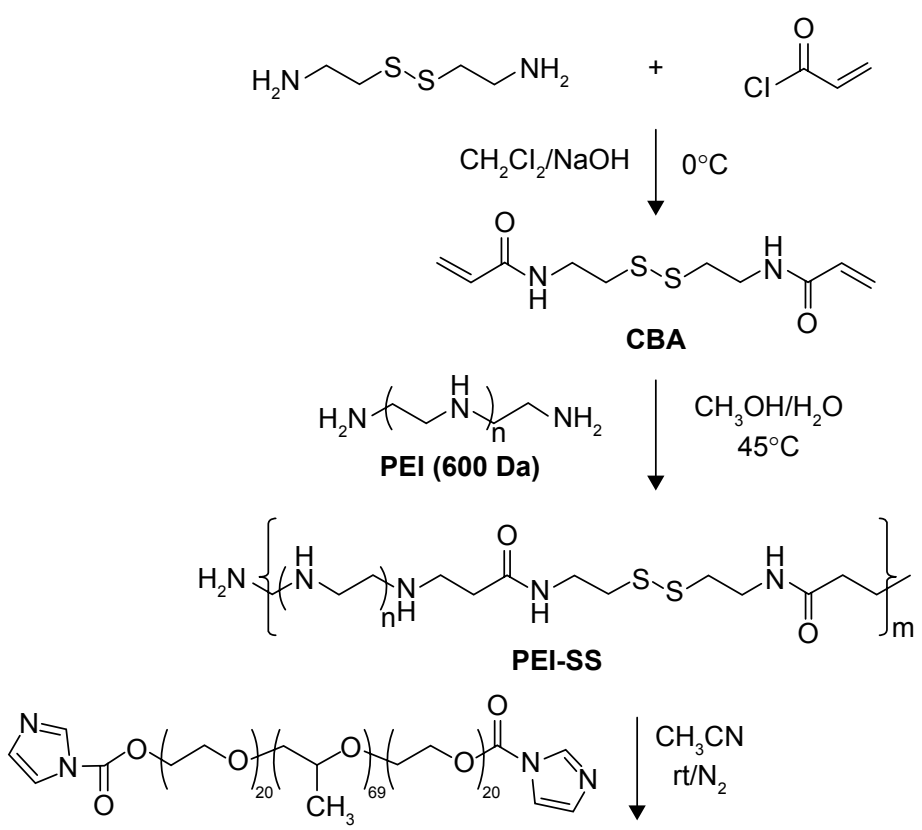

CDI-Pluronic
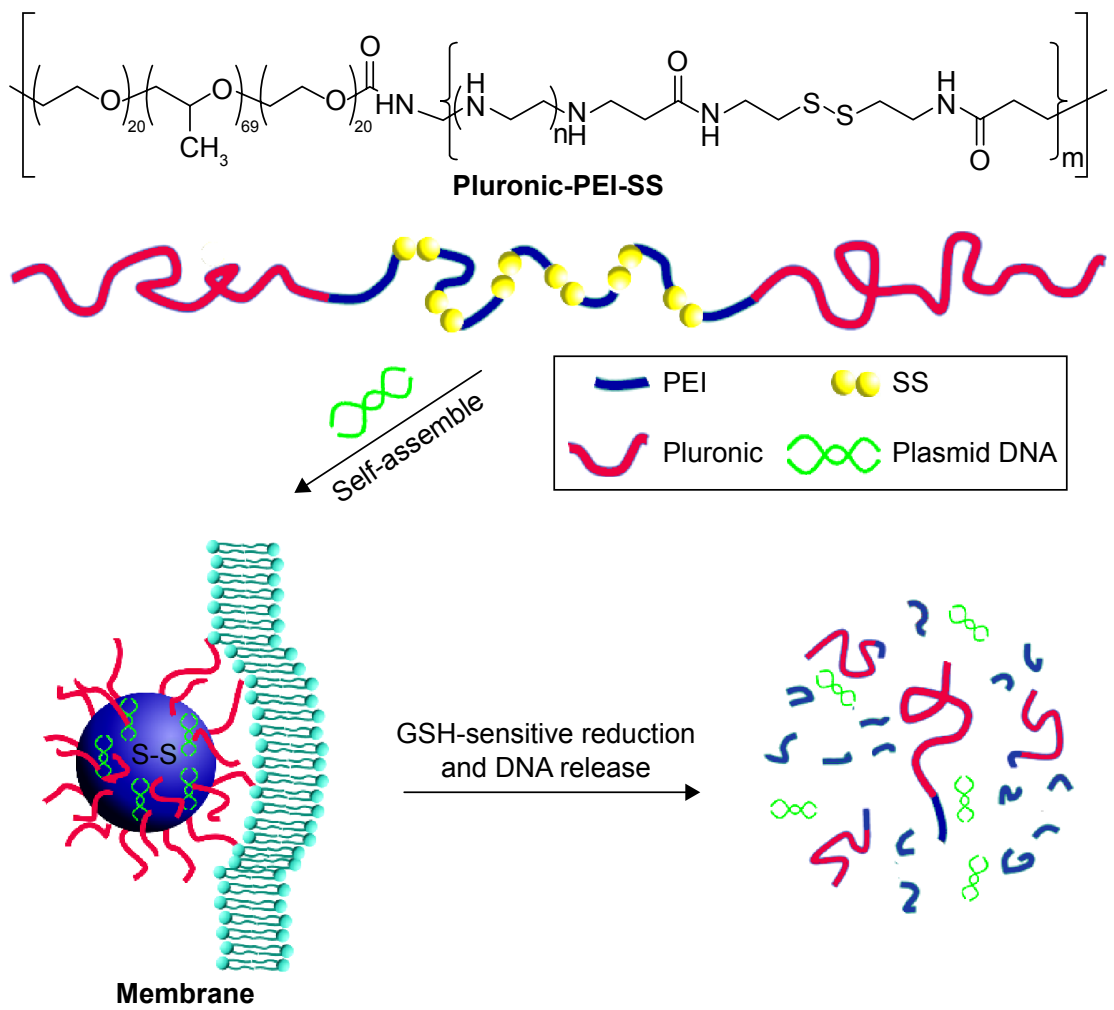

Figure I Synthesis of Pluronic-PEI-SS and schematic of the redox-responsive disassembly of Pluronic-PEI-SS/DNA complex in cells.

Abbreviations: CBA, cystamine bisacrylamide; PEI, polyethyleneimine; PEI-SS, disulfide-linked PEI; rt, room temperature; CDI, I,I'-carbonyldiimidazole; GSH, green fluorescent protein.

using Pluronic-PEI as control. In brief, each copolymer $(1 \mathrm{~g})$ dissolved in PBS (2 mL, $\mathrm{pH}$ 7.4) was incubated with or without DTT $(310 \mathrm{mM})$ at $37^{\circ} \mathrm{C}$ with shaking at $100 \mathrm{rpm}$ for specified times. Then, the samples were frozen immediately in liquid nitrogen, lyophilized, and measured by GPCMALLS to determine their molecular weights.

\section{Preparation of complexes}

To form polymer (Pluronic-PEI-SS, Pluronic-PEI, or PEI 25 $\mathrm{kDa}) / \mathrm{DNA}$ complexes, pDNA (1 $\mu \mathrm{g}$ ) dissolved in PBS ( $\mathrm{pH} 7.4)$ was mixed with various amounts of polymer in PBS at various N/P (nitrogen to phosphate) ratios, vortexed for a short time, and further incubated at room temperature for 30 minutes. 


\section{Gel retardation assay}

DNA condensing ability of Pluronic-PEI-SS, Pluronic-PEI, or PEI $25 \mathrm{kDa}$ was examined by agarose gel electrophoresis. The polymer/DNA complexes at various N/P ratios were prepared and dissolved separately in $0.8 \%$ agarose at $\mathrm{pH} 7.5$ by vigorous pipetting. The mixtures were incubated for 30 minutes at room temperature. Then, the mixture was electrophoresed on $0.8 \%$ agarose gel stained with ethidium bromide $(0.1 \mu \mathrm{g} / \mathrm{mL})$ at $80 \mathrm{~V}$ for 80 minutes, visualized by an ultraviolet (UV) $(254 \mathrm{~nm})$ illuminator and photographed with a gel imaging system (Kodak In-Vivo Imaging System FX Pro; Kodak, Rochester, NY, USA).

The stability of Pluronic-PEI-SS/DNA complex against deoxyribonuclease I (DNase I) digestion and reducing agent DTT was further investigated, respectively, using DNA as control. The samples were divided into three groups. The first group was treated with DNase I (1-2 units) for 30 minutes at $37^{\circ} \mathrm{C}$. The second group was treated with different amounts of reductive reagent DTT $(0,0.5,2.5,12.5,62.5$, and $310 \mathrm{mM}$ ). The treated and untreated samples were then loaded on $0.8 \%$ agarose gel, stained with ethidium bromide, and photographed by gel imaging system.

\section{Particle size and zeta potential measurements}

The particle sizes and surface charges of complexes at various N/P ratios were measured at room temperature using a Zetaplus Zeta Potential Analyzer (Brookhaven Instrument Corp., Holtsville, NY, USA) equipped with a $15 \mathrm{mV}$ solid-state laser operated at a wavelength of $635 \mathrm{~nm}$ and an angle of $90^{\circ}$.

\section{Transmission electron microscopy}

The morphologies of the Pluronic-PEI-SS/DNA complexes (N/P of 20) dependent on DTT were assessed by transmission electron microscopy (TEM). A drop of the solution with (or without) $310 \mathrm{mM}$ DTT was placed on a Formvar precoated carbon grid for 30 minutes. Then, the samples were stained with $1 \%$ phosphotungstic acid for 15 minutes and analyzed using a JEM-1230 TEM microscope (JEOL, Tokyo, Japan) at $100 \mathrm{kV}$.

\section{MTT assay}

Human embryonic kidney transformed 293 (293T) and human cervical carcinoma cell line (HeLa) were incubated in DMEM with $10 \%$ FBS and $1 \%$ antibiotic solution (penicillin-streptomycin, $10,000 \mathrm{U} / \mathrm{mL}$ ) at $37^{\circ} \mathrm{C}$ in a humidified atmosphere containing $5 \% \mathrm{CO}_{2}$. Herein, MTT assay was carried out to evaluate the cytotoxicity of the complexes for different HeLa and 293T cells. Briefly, the cells were seeded in a 96-well plate at a density of 7,000 cells/well, and then incubated in $100 \mathrm{~mL}$ of DMEM with $10 \%$ FBS under a humidified atmosphere of $95 \%$ air and $5 \% \mathrm{CO}_{2}$ for 24 hours. After that, the medium was replaced with $90 \mu \mathrm{L}$ of fresh medium and the solutions $(10 \mu \mathrm{L})$ of $25 \mathrm{kDa}$ PEI, PEI-SS, Pluronic-PEI, or Pluronic-PEI-SS were added. After 48 -hour treatment, MTT reagent $(5 \mathrm{mg} / \mathrm{mL}, 10 \mu \mathrm{L}$ in PBS) was injected into each well for incubation for another 4 hours at $37^{\circ} \mathrm{C}$. To each well was added $100 \mu \mathrm{L}$ of DMSO to dissolve the crystals, and then the medium was removed and DMSO $(100 \mathrm{~mL})$ was added and the absorbance of the solution was measured at $570 \mathrm{~nm}$ via a microplate reader (model 550; Bio-Rad Laboratories Inc., Hercules, CA, USA). The relative cell viability was calculated as follows: Viability $(\%)=\left(\mathrm{OD}_{\text {sample }}-\mathrm{OD}_{\text {blank }}\right) /\left(\mathrm{OD}_{\text {control }}-\mathrm{OD}_{\text {blank }}\right) \times 100$, where $\mathrm{OD}_{\text {sample }}$ is the absorbance of the solution of the cells cultured with the polymer or PEI, $\mathrm{OD}_{\text {blank }}$ is the absorbance of the medium, and $\mathrm{OD}_{\text {control }}$ is the absorbance of the solution of the cells cultured with the medium only.

\section{In vitro transfection}

For transfection experiment, pEGFP was used to assess the transfection efficiency of the complexes including PluronicPEI-SS, PEI-SS, Pluronic-PEI, and $25 \mathrm{kDa}$ PEI. Two different cells of HeLa and $293 \mathrm{~T}$ were seeded in a 24-well plate at a density of $5 \times 10^{4}$ cells/well. The cells were incubated at $37^{\circ} \mathrm{C}$ in a humidified atmosphere of $95 \%$ air and $5 \% \mathrm{CO}_{2}$ for 24 hours. The medium in each well was replaced with DMEM $(1 \mathrm{~mL}$ ) without FBS. The complexes with the N/P ratios from 10 to 40 (the amount of DNA added to each well was kept at $1 \mu \mathrm{g}$ ) were added to the cells and incubated for 4 hours at $37^{\circ} \mathrm{C}$. The medium was then replaced with fresh DMEM medium ( $1 \mathrm{~mL}$ ) with $10 \% \mathrm{FBS}$, for further 48-hour incubation. After that, the cells were separately harvested from wells by treatment with trypsin-ethylenediaminetetraacetic acid and suspended in microcentrifuge tubes with $1 \mathrm{~mL}$ PBS. The cells expressing green fluorescent protein were enumerated by fluorescence-activated cell sorting (FACSCanto ${ }^{\mathrm{TM}}$; BD Biosciences, San Jose, CA, USA).

\section{Subcellular distribution}

HeLa cells were seeded into six-well plates, $1 \times 10^{5}$ cells every well, and then cultured overnight in a cell incubator. The indicated complexes were mixed with Cy5-labeled plasmid and incubated for 30 minutes. For transfection, cell medium was changed with fresh complete medium, and then the complexes were added into the above medium. This was followed by 4 hours' incubation. To examine the subcellular 
distribution, confocal and real-time polymerase chain reaction (PCR) assays were performed. The cells were stained with 4',6-diamidino-2-phenylindole (DAPI), followed by observation with confocal laser scanning microscopy (Olympus FV1000; Olympus, Tokyo, Japan). Other cells were collected and used for nucleocytoplasmic separation, and then real-time PCR was performed using nuclear and cytoplasmic fractions as template.

\section{In vivo transfection and expression}

Male nude mice 4-5 weeks old and weighing 18-22 g were separated into three groups (five mice per group), and then subcutaneously injected with $2.4 \times 10^{6} \mathrm{HeLa}$ cells to establish the tumor models. When the size of the transplanted tumors increased to $10 \mathrm{~mm}$ in diameter, at the 20 th day, $200 \mu \mathrm{L}$ of the sterilized complexes solution containing $50 \mu \mathrm{g}$ of the pGL4-control or EGFP reporter gene was injected into the mice through the tail veins. The details of the complexes injected were as follows: Group 1, Pluronic-PEI-SS/DNA complexes with the N/P of 20; Group 2, PEI $25 \mathrm{KDa} / \mathrm{DNA}$ complexes with the N/P of 10; Group 3, free DNA. Twentyfour hours postinjection, the mice were sacrificed to collect the tumors. The tissues such as heart, liver, spleen, kidney, brain, and tumors were collected and homogenized in a cell lysis buffer. The cell lysate was centrifuged. After being centrifuged for 10 minutes at $10,000 \mathrm{rpm}$, an aliquot of the supernatant with pGL4-control was assayed for luciferase activity using a commercial kit and photon counting was performed with a luminometer.

The above collected the tumors expressing GFP protein, and embedded them in Tissue-Tek OCT, cooled quickly to $-80^{\circ} \mathrm{C}$, and sectioned with cryostat. The sections with size of $20 \mathrm{~mm}$ were put on Superfrost microscope slides and dried for 1 hour at room temperature and then kept at $-80^{\circ} \mathrm{C}$ for subsequent use. The GFP fluorescence (excitation $488 \mathrm{~cm}^{-1}$ ) of the obtained samples was assessed by Zeiss 410 confocal laser scanning microscope equipped with an argon-krypton laser.

\section{Statistical analysis}

The statistical calculations between two sets of data were carried out using Student's $t$-test software and differences were considered significant if $P \leq 0.05$.

\section{Results and discussion Synthesis and characterization of Pluronic-PEI-SS conjugate copolymer}

The synthesis route for Pluronic-PEI-SS is illustrated in Figure 1. PEI-SS was synthesized by conjugating PEI and cystamine bisacrylamide. Figure $2 \mathrm{~A}$ shows the ${ }^{1} \mathrm{H}$ NMR spectrum of PEI-SS to confirm its chemical structure. The characteristic proton peaks between 2.5 and $3.0 \mathrm{ppm}$ may be attributed to the special shift of PEI. It was found that acrylamide peaks between 5.8 and $6.5 \mathrm{ppm}$ disappeared, indicating that PEI-SS was successfully prepared. PluronicPEI-SS (or Pluronic-PEI) was purified by dialysis to remove the unreacted PEI-SS (or PEI), unconjugated Pluronic, and other small molecules. The structures of Pluronic-PEI and Pluronic-PEI-SS were also determined by the ${ }^{1} \mathrm{H}$ NMR spectra (Figure 2B and C).

The calculated composition of Pluronic to PEI-SS is $\sim 0.5$. The molecular weights and polydispersity indices of the three polymers were determined by GPC-MALLS. As shown in Table 1, the characteristics of the synthesized polymers were obtained, and the number average molecular weights $\left(\mathrm{M}_{\mathrm{n}}\right)$ of Pluronic-PEI-SS and Pluroic-PEI were $\sim 27$ and $26 \mathrm{kDa}$, respectively.

\section{Degradation of Pluronic-PEI-SS}

Generally, disulfide bonds are susceptible to cleavage in the presence of DTT at physiological conditions. ${ }^{19}$ Herein, the degradation of Pluronic-PEI-SS was determined by its molecular weight changes, dependent on DTT, at $37^{\circ} \mathrm{C}$, using Pluronic-PEI as control. Figure 3 displays the molecular weight profiles of the copolymers with (or without) DTT as a function of time. It was found that in the absence of DTT, Pluronic-PEI-SS hardly degraded and had little difference with Pluronic-PEI, while in the presence of DTT, Pluronic-PEI-SS degraded to a greater extent than Pluronic-PEI. Pluronic-PEI-SS was almost completely degraded within 10 hours in the presence of DTT and the molecular weights were kept relatively constant at $\sim 5,000 \mathrm{Da}$ even at 50 hours. These results indicate that Pluronic-PEI-SS including disulfide bonds has a rapid degradation in the reductive conditions and would display a rapid cleavage in the cytosol, which facilitates DNA release from the complex in gene delivery system.

\section{Characterizations of the complexes}

The Pluronic-PEI-SS/DNA complexes at various N/P ratios ranging from 0 to 40 were prepared and measured by a NanoZeta Sizer at $25^{\circ} \mathrm{C}$. As shown in Figure 4A, the particle size of the complexes gradually diminished on increasing the N/P ratio. The diameter of the Pluronic-PEI/DNA and PEI-SS/DNA complexes remained large $(\sim 200 \mathrm{~nm})$ at even a high N/P ratio of 30 or 40, while the average particle size of Pluronic-PEI-SS/DNA complexes was smaller than $200 \mathrm{~nm}$ at the $\mathrm{N} / \mathrm{P}$ ratio of 20 . Figure $4 \mathrm{~B}$ shows that as the $\mathrm{N} / \mathrm{P}$ ratio increased, the negative charge of the complexes was almost 
fully neutralized and even slightly positive at the N/P ratio of 30 , due to the progressive neutralization by the charged amino groups of PEI-SS segments.

As shown in Figure 5A and B, Pluronic-PEI-SS can start to form complexes at an N/P ratio of 5, but PEI-SS can complete the neutralization of DNA even at a lower N/P ratio of 3. This result demonstrates that although Pluronic shields the partially positive charges of the Pluronic-PEI-SS/ DNA complex surface, the complex displays a high affinity with DNA.

We proposed that Pluronic-PEI-SS/DNA complexes containing bioreducible disulfide bonds can be kept stable in the extracellular environment, while they dissociate easily under intracellular reducing conditions due to the disulfide cleavage. $^{23,24}$ To prove this proposition, the stability of the Pluronic-PEI-SS/DNA complex against nucleases was assessed by agarose gel electrophoresis to find out whether the complex can protect DNA from being degraded by nucleases. As shown in Figure 5C, Pluronic-PEI-SS/DNA complex can protect DNA from degradation even with a high concentration of DNase I ( 1 or 2 units/ $\mu$ g DNA), while the naked DNA was completely degraded by DNase I. Then, the stability of Pluronic-PEI-SS/DNA complex in the presence of DTT as cross-link sulfhydryl-reducing agent was further evaluated by gel electrophoresis assay. Figure 5D shows the effect of DTT concentration ranging from 0.5 to $310 \mathrm{mM}$

A
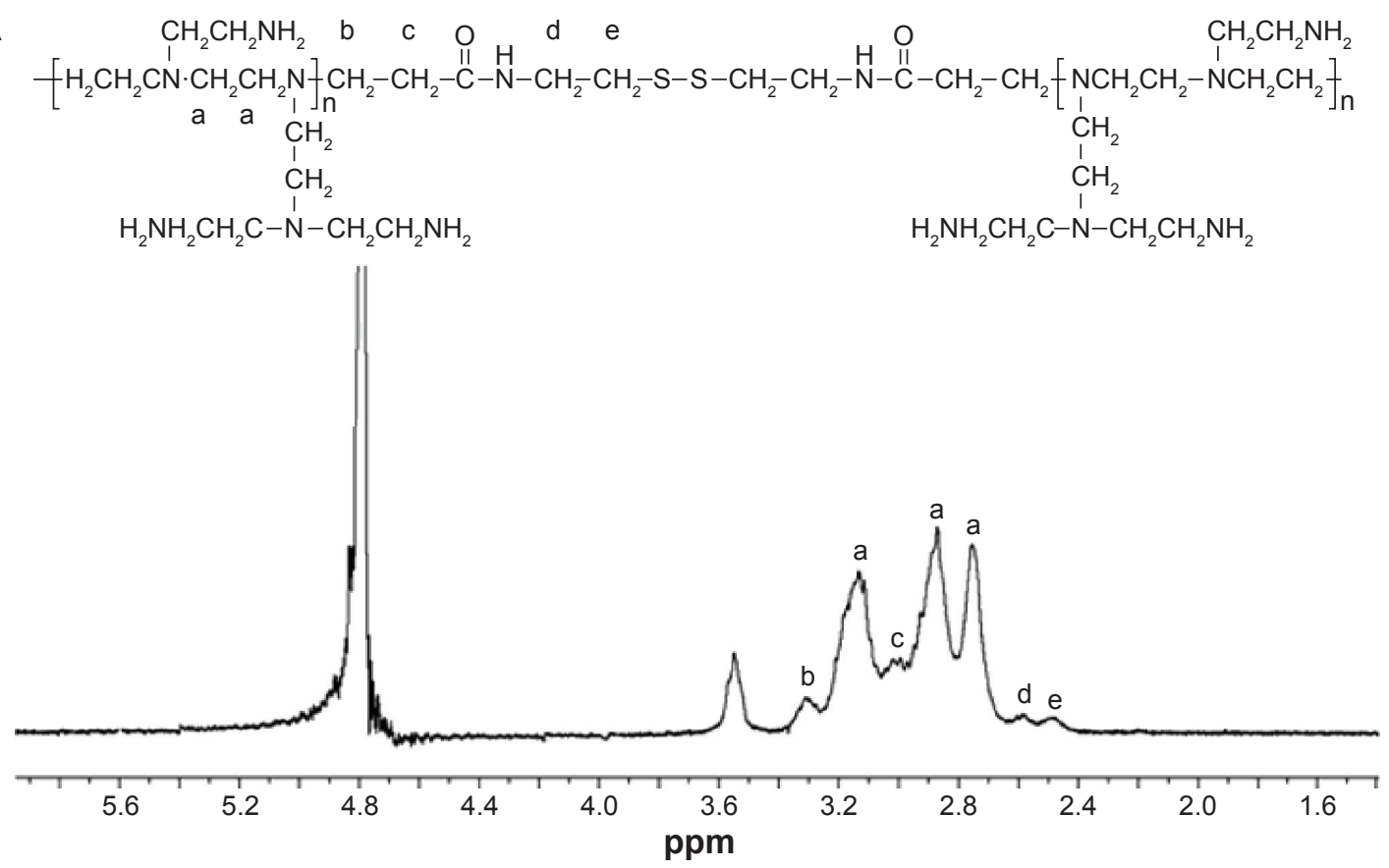

B

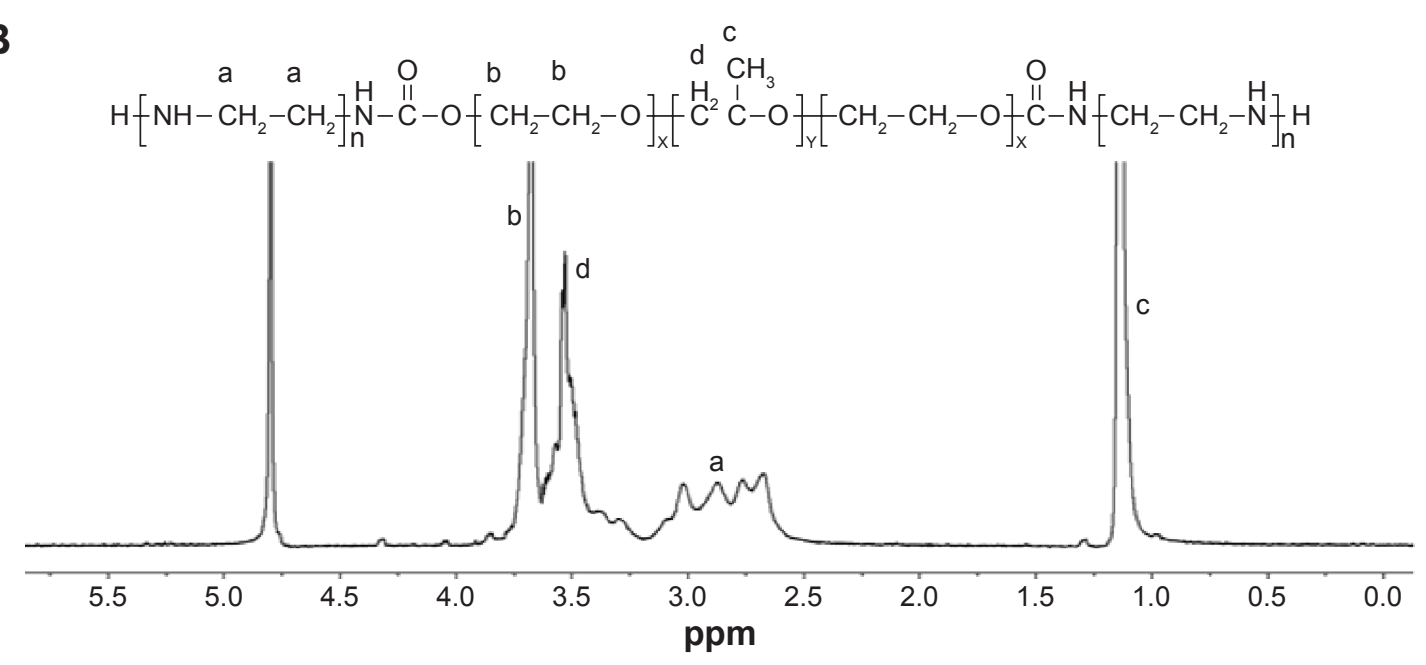

Figure 2 (Continued) 


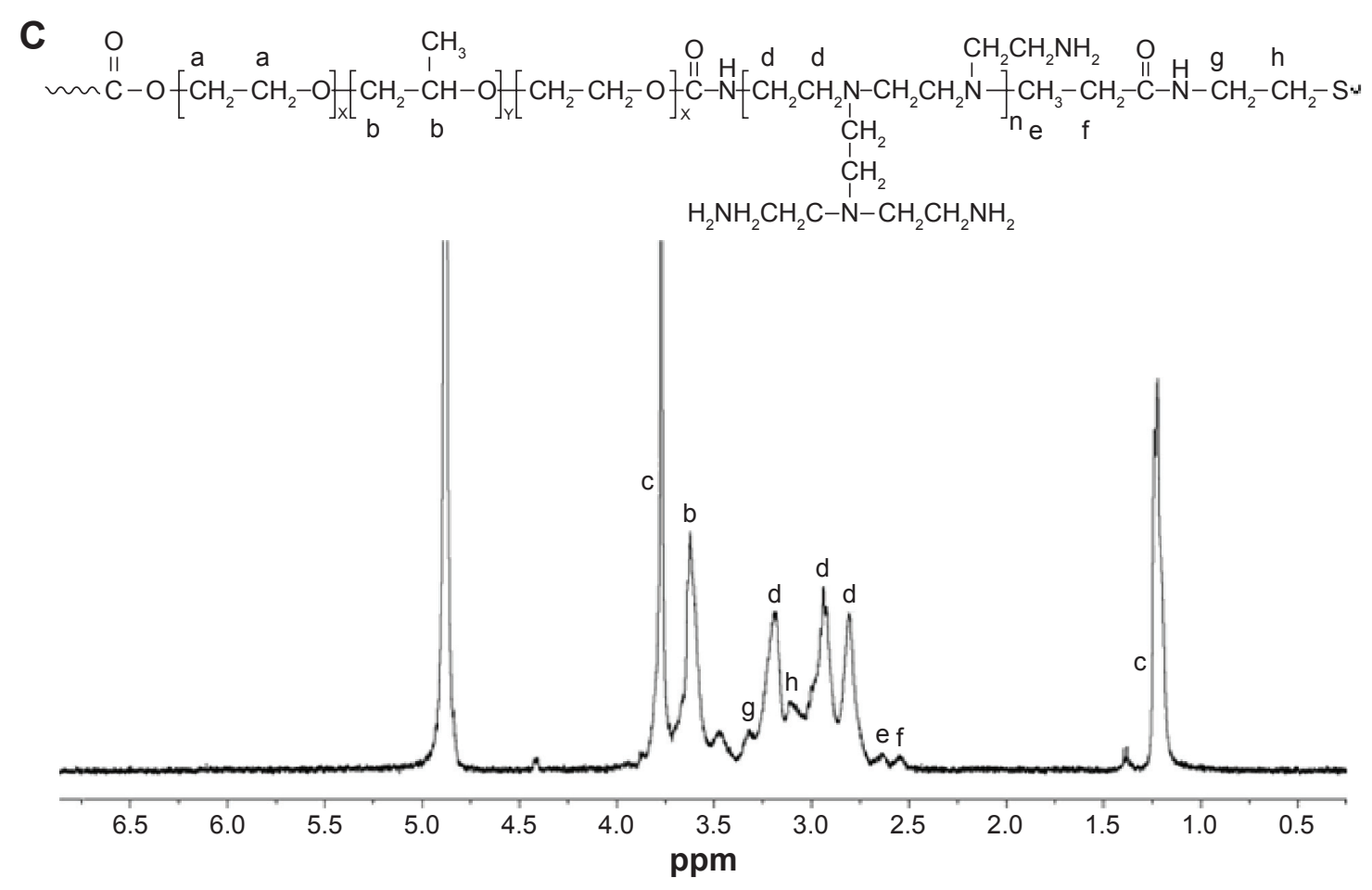

Figure 2 'H NMR spectra of PEI-SS (A), Pluronic-PEI (B), and Pluronic-PEI-SS (C) in $\mathrm{D}_{2} \mathrm{O}$.

Note: Lowercase letters $(a-h)$ shown above peaks indicate different proton chemical shifts.

Abbreviations: PEI, polyethyleneimine; 'H NMR, proton nuclear magnetic resonance; PEI-SS, disulfide-linked PEI; $\mathrm{D}_{2} \mathrm{O}$, heavy water.

on the stability of the complex with N/P ratio of 5 . It was found that DNA gradually migrated with increasing concentration of DTT, suggesting the rapid release of DNA in the reducible conditions. The results suggest that the degradable Pluronic-PEI-SS complexes are capable of not only forming stable complexes with DNA from nuclease digestion but also enhancing the DNA release from the complex in cytoplasm under extreme reducing conditions.

The dependence of DTT on morphology behavior of the Pluronic-PEI-SS/DNA complex was confirmed by TEM. As shown in Figure 6, the Pluronic-PEI-SS/DNA complex with a uniform size of $\sim 80 \mathrm{~nm}$ at a representative N/P ratio of 20 was observed and well defined. However, the complexes swelled from 80 to $150 \mathrm{~nm}$ after DTT treatment. According

Table I Characteristics of PEI-SS, Pluronic-PEI-SS, and PluronicPEl polymers

\begin{tabular}{lllll}
\hline Polymer & $\mathbf{M}_{\mathbf{w}}{ }^{\mathrm{a}}(\mathrm{Da})$ & $\mathbf{M}_{\mathrm{n}}{ }^{\mathrm{a}}(\mathrm{Da})$ & PDI $^{\mathrm{a}}$ & $\begin{array}{l}\text { Molar } \\
\text { ratio }^{\mathrm{b}}\end{array}$ \\
\hline PEI-SS & 25,550 & $21,29 \mathrm{I}$ & $\mathrm{I} .2$ & 1.00 \\
Pluronic-PEI-SS & 38,210 & 27,221 & 1.4 & 0.45 \\
Pluronic-PEI & 33,780 & 26,896 & 1.3 & 0.24 \\
\hline
\end{tabular}

Notes: a Molecular weight $\left(M_{w}\right)$, number average molecular weights $\left(M_{n}\right)$, and PDI were determined by GPC-MALLS; ${ }^{b}$ molar ratio of PEl to Pluronic in the copolymers was determined by their 'H NMR spectra.

Abbreviations: PDI, polydispersity index; PEI, polyethyleneimine; PEI-SS, disulfidelinked PEI; GPC-MALLS, gel permeation chromatography-multi-angle laser light scattering; 'H NMR, proton nuclear magnetic resonance. to the GSH concentration-dependent deshielding kinetics character in the tumor tissues, the redox-responsive complex could keep stable during the circulation ( $5 \mu \mathrm{M} \mathrm{GSH})$, slightly loosened when reaching the tumor site (20 $\mu \mathrm{M} \mathrm{GSH})$, and further detached from the complex in the intracellular environment (5 mM GSH). We suggest that Pluronic-PEI-SS with a suitable nanosize and a dependence on the reducible environment would facilitate the nanocarrier to enter into cells and rapidly enhance the DNA release in cytoplasm.

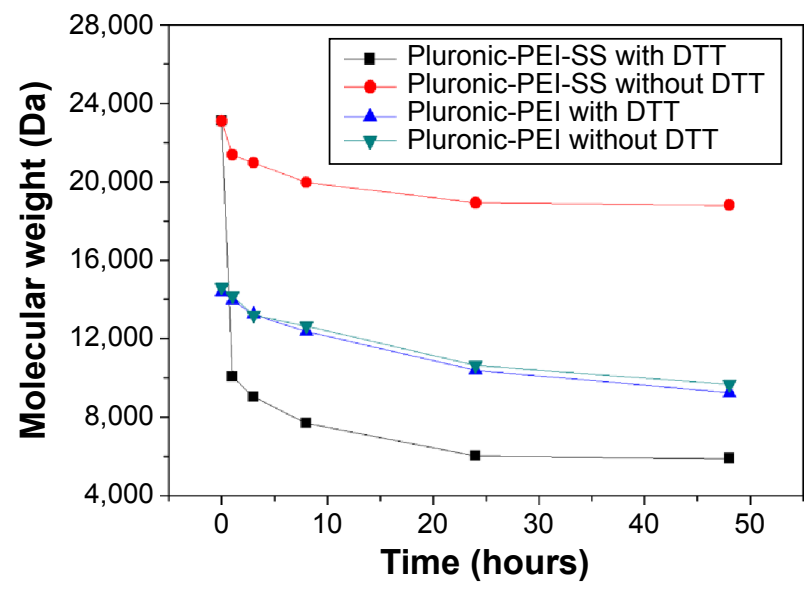

Figure 3 Degradation behaviors of Pluronic-PEI-SS in the presence (or absence) of DTT (310 mM), using Pluronic-PEl as control.

Abbreviations: PEI, polyethyleneimine; DTT, I,4-dithiothreitol; PEI-SS, disulfidelinked PEI. 

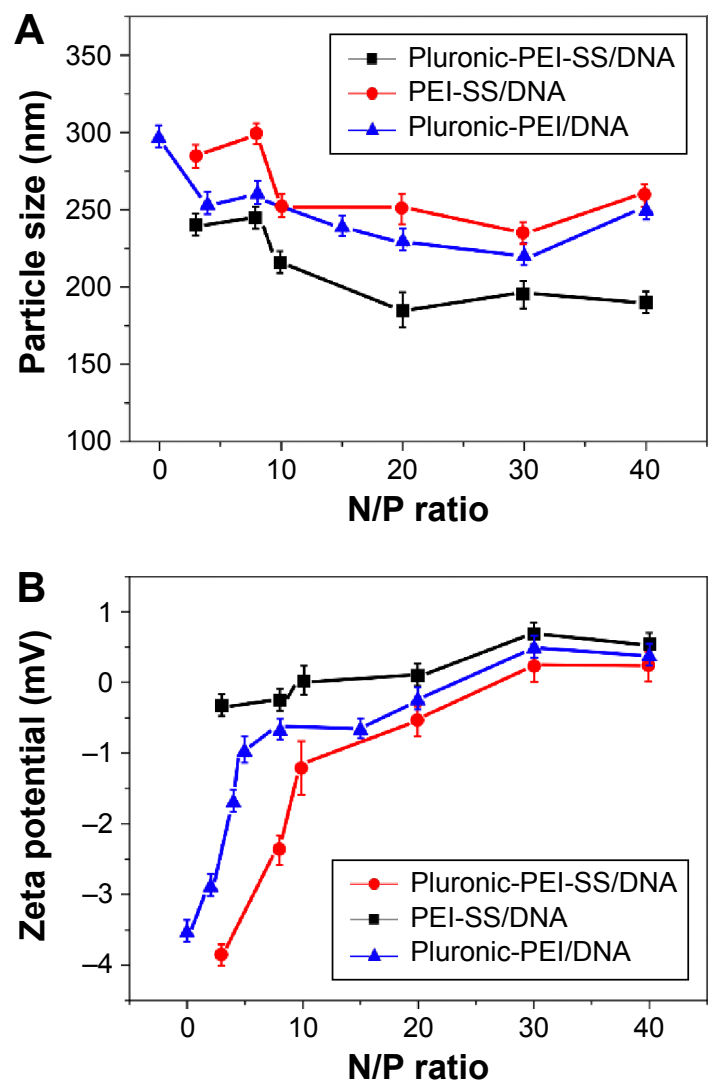

Figure 4 (A) Size and (B) zeta potential of the DNA complexes with Pluronic-PEI-SS, Pluronic-PEI, or PEI-SS measured by DLS and a zeta potential analyzer at various N/P ratios.

Abbreviations: PEl, polyethyleneimine; PEI-SS, disulfide-linked PEI; N/P, nitrogen to phosphate; DLS, dynamic light scattering.

\section{Cytotoxicity}

To investigate the biocompatibility of this delivery system for potential application in gene delivery, the cytotoxicity of Pluronic-PEI-SS toward HeLa and 293T cells was carried out by MTT assay, using Pluronic-PEI, PEI-SS, and PEI $25 \mathrm{kDa}$ as controls. As shown in Figure 7A, the cell viability of HeLa cells treated with PEI $(25 \mathrm{kDa})$ at $0.10 \mathrm{mg} / \mathrm{mL}$ was lower than $20 \%$, indicating the high toxicity of PEI $(25 \mathrm{kDa})$, whereas the cell viability after treatment with PEI-SS at the same concentration was $85 \%$ due to the biodegradable disulfide-linked low-molecular-weight PEI. Pluronic-PEI-SS and PluronicPEI copolymers exhibited relatively higher cell viability in comparison to PEI-SS and PEI $25 \mathrm{kDa}$. The reduction in cytotoxicity is the result of the conjugation of biocompatible Pluronic polymers and their steric shielding capable of reducing the aggregation of the positive charge on the cell surface. Especially, even at the higher concentrations used in comparison with the controls, Pluronic-PEI-SS still showed the highest cell viability, suggesting that reducible disulfide bonds and Pluronic modification attributed to good biocompatibility of the copolymer. Very similar cell viability results were also observed for the 293T cells (Figure 7B).

\section{In vitro transfection}

In vitro transfection efficiency of Pluronic-PEI-SS into HeLa and $293 \mathrm{~T}$ cells was investigated using the pGL4 encoding
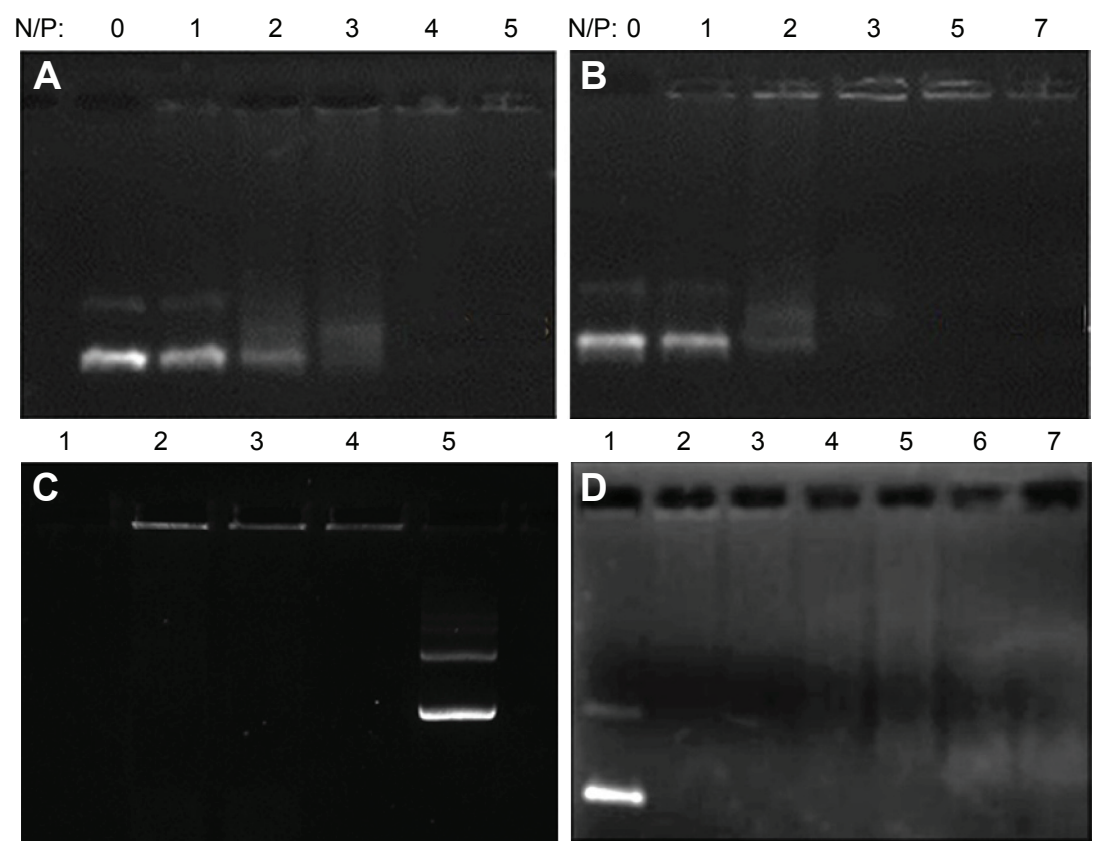

Figure 5 Agarose gel eletrophoresis analysis.

Notes: Retardation assay for Pluronic-PEI-SS/DNA (A) and PEI-SS/DNA complexes (B) at the N/P ratios ranging from I to 7. (C) DNase I protection assay for Pluronic-PEI-SS/ DNA complex (N/P =20). From left: lane 0, naked DNA; lane I, naked DNA with DNase I (I unit); lane 2, Pluronic-PEI-SS/DNA (N/P =20) treated with DNase I (I unit); lane 3, Pluronic-PEI-SS/DNA with DNase I (2 units); lane 4, Pluronic-PEI-SS/DNA; lane 5, naked DNA. (D) Retardation assay for Pluronic-PEI-SS/DNA (N/P =20) post-treated with reductive reagent DTT. From left: lane I, naked DNA; lane 2, Pluronic-PEI-SS/DNA; lanes 3-7, Pluronic-PEI-SS/DNA with 0.5, 2.5, I2.5, 62.5, and 3I0 mM DTT, respectively. Abbreviations: PEl, polyethyleneimine; DTT, I,4-dithiothreitol; N/P, nitrogen to phosphate; PEI-SS, disulfide-linked PEI; DNase I, deoxyribonuclease I. 

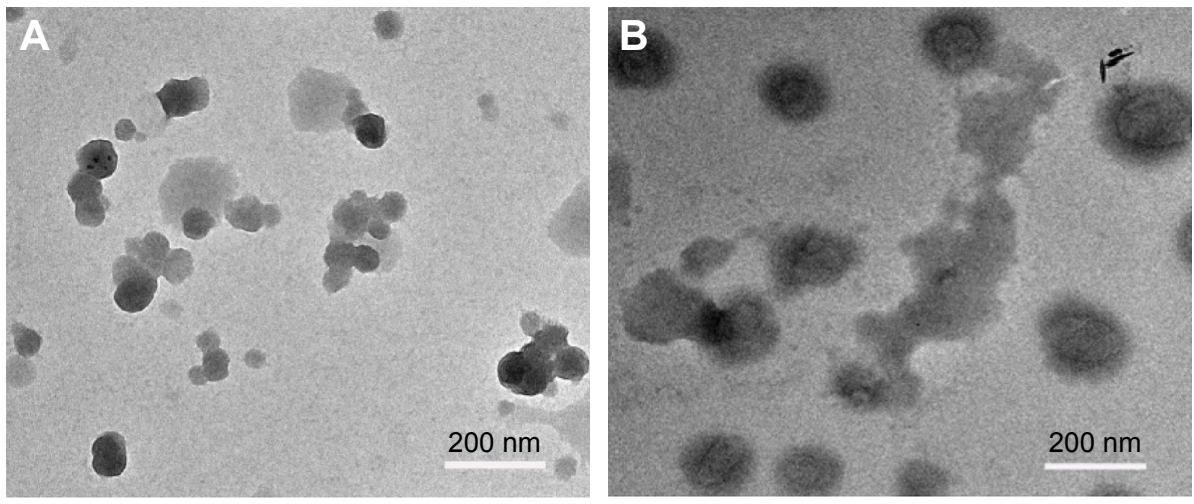

Figure 6 TEM images of Pluronic-PEI-SS/DNA complex (N/P of 20) without (A) or with (B) DTT (310 mM).

Abbreviations: TEM, transmission electron microscopy; PEI, polyethyleneimine; DTT, I,4-dithiothreitol; N/P, nitrogen to phosphate; PEI-SS, disulfide-linked PEI.

EGFP-N1 (pEGFP plasmid) as reporter gene, and PEI-SS/ pDNA, Pluronic-PEI/pDNA, and PEI-25 kDa/pDNA used as controls. As shown in Figure 8, the Pluronic-PEI-SS showed the highest transfection efficacy among these complexes at the N/P ratio of 30 in HeLa cells, which was approximately four, three, and even 13 times as much as that for PluronicPEI, PEI-SS, and $25 \mathrm{kDa}$ PEI, respectively (Figure 8A). Similar results were observed in 293T cells (Figure 8B). Thus, the conjugation of Pluronic and disulfide bonding in Pluronic-PEI-SS chains could enhance the gene transfection efficiency of the HeLa and 293T cells.

\section{Intracellular trafficking}

Conjugation of Pluronic with PEI-SS significantly improved both cellular uptake and transfection efficiency, possibly due to the facilitated translocation of pDNA into the nucleus by Pluronic residues and degradable PEI-SS. To prove this hypothesis, we investigated the subcellular location and delivery processes of Pluronic-PEI-SS/DNA complexes, using Pluronic-PEI, PEI-SS, and PEI $25 \mathrm{kDa}$ as controls. pDNA was labeled with Cy5, and nucleus was stained with DAPI. As shown in Figure 9A, it was revealed that there was a considerably greater colocalization in the nucleus for PluronicPEI-SS/DNA than for the other four complexes at 4-hours post-transfection, indicating the disulfide bonding of PEI-SS and Pluronic residues could efficiently translocate PluronicPEI-SS/DNA into the nucleus. The ability of Pluronic-PEI-SS/ DNA to enhance translocation is consistent with the previous findings. ${ }^{11,12}$

To further explore their nuclear localization, nucleocytoplasmic separation experiment was carried out to determine the concentration of pEGFP-N1 in the nuclear section (Figure 9B). HeLa cells were post-transfected with these four complexes and incubated for 4 hours, and then the cells were collected and the nuclear section was extracted. Using the nuclear section as template, the concentration of pEGFP-N1
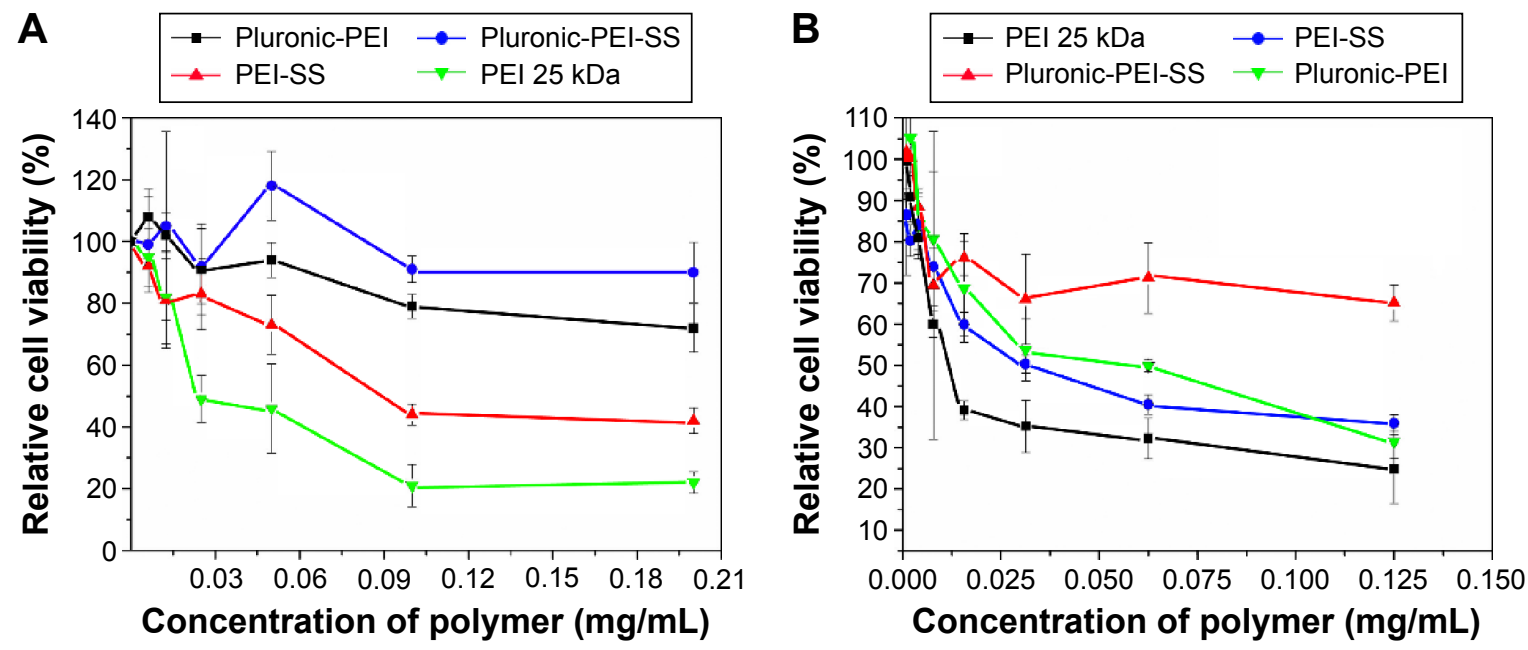

Figure 7 Cytotoxicity assays of Pluronic-PEI-SS at various concentrations in HeLa (A) and 293T (B) cells; Pluronic-PEI, PEI-SS, and PEl 25 kDa used as controls. Note: Data are presented as mean \pm SD $(n=3)$.

Abbreviations: PEI, polyethyleneimine; PEI-SS, disulfide-linked PEI; SD, standard deviation. 

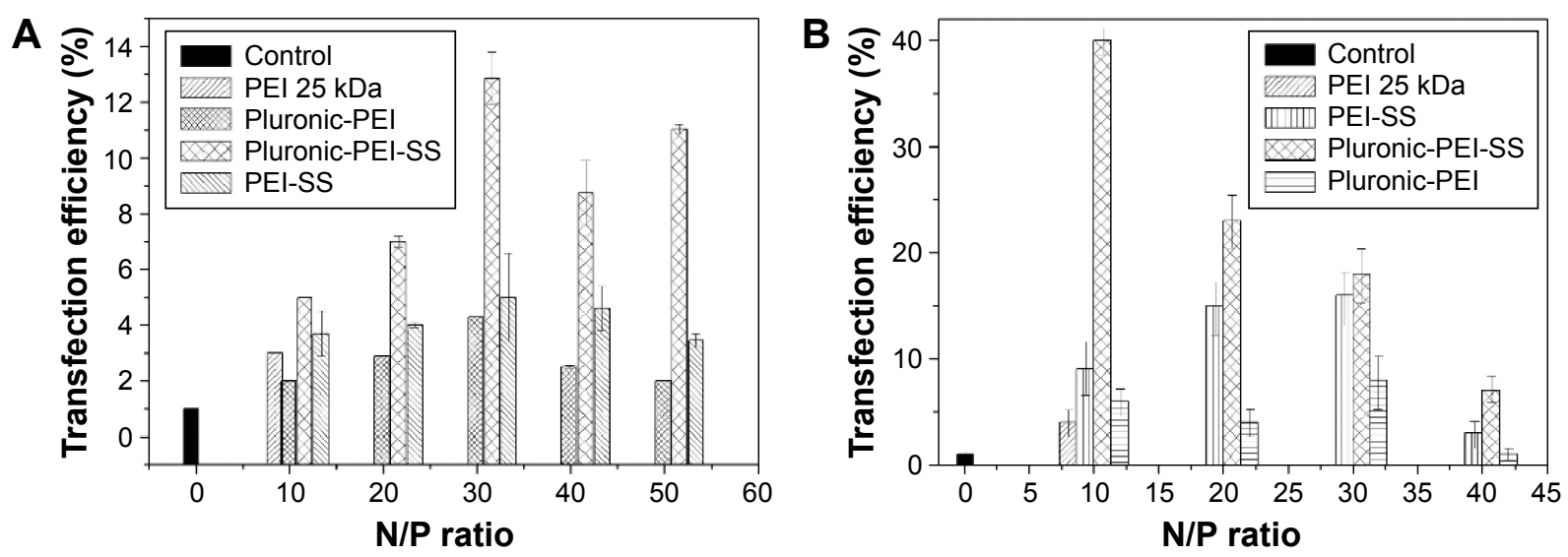

Figure 8 The percentage of EGFP-expressing HeLa (A) and 293T (B) cells for Pluronic-PEI-SS determined by flow cytometry, using Pluronic-PEl, PEI-SS, and 25 kDa PEI as controls.

Note: Data are presented as mean \pm SD $(n=3)$

Abbreviations: EGFP, enhanced green fluorescent protein; PEI, polyethyleneimine; PEI-SS, disulfide-linked PEI; SD, standard deviation; N/P, nitrogen to phosphate.

in the nucleus was determined by real-time PCR. The results demonstrated that Pluronic-PEI-SS/DNA displayed the highest copy number of pEGFP-N1 and delivery efficiency among these nanocomplexes, which is consistent with the confocal data. In summary, efficient translocation of the Pluronic-PEI-SS/DNA complex into the nucleus may have resulted in effective transfection.

\section{In vivo transfection}

Their excellent transfection ability and low toxicity in vitro encouraged assessment of the gene expression of
Pluronic-PEI-SS/DNA complex in vivo. Accordingly, male nude mice bearing HeLa cells were administered, by tail vein injection, pGL4-control reporter DNA complex. At 24-hours postinjection, mice were sacrificed to collect heart, liver, spleen, lung, kidney, and tumor. Tissue distribution of gene expression was assayed along with a corresponding nanocomplex. Compared with free naked DNA and PEI/DNA, Pluronic-PEI-SS/DNA exhibited significantly higher gene expression of luciferase in all parts of tissues. As shown in Figure 10A, gene expression of luciferase for the Pluronic-PEI-SS/DNA in liver, spleen, and tumor

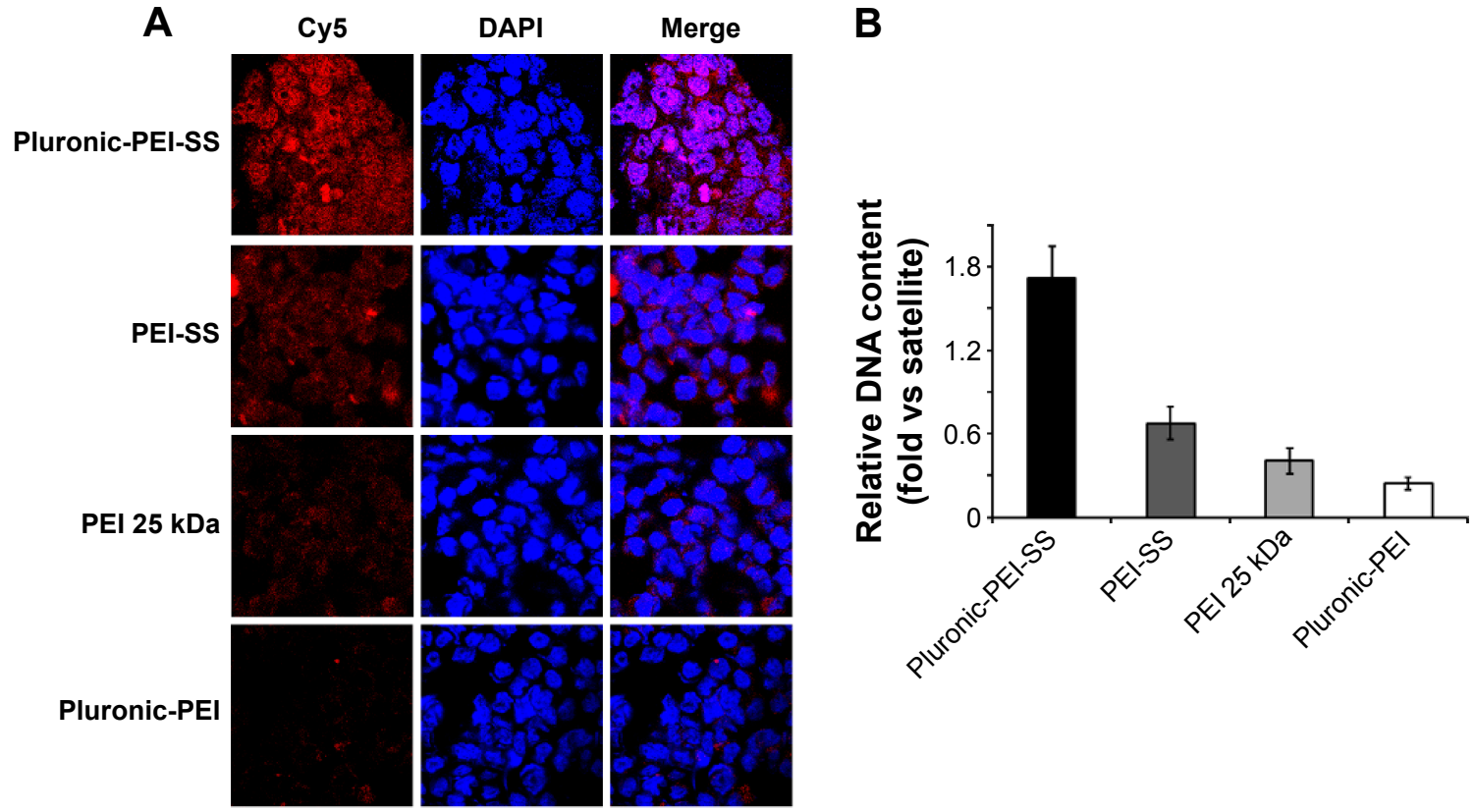

Figure 9 Cellular uptake of the nanocomplexes in HeLa cells.

Notes: (A) Subcellular fluorescent images of the four different nanocomplexes in HeLa cells post-transfected for 4 hours. pDNA was stained with Cy5 (red), and nucleus was stained with DAPI (blue). (B) The indicated cells were collected for nucleocytoplasmic separation, and then nuclear and cytoplasmic DNA contents were analyzed using real-time PCR; satellite DNA served as loading control.

Abbreviations: PCR, polymerase chain reaction; PEI, polyethyleneimine; PEI-SS, disulfide-linked PEl; Cy5, 2-([IE,3E,5E]-5-[I-\{5-carboxypentyl\}-3,3-dimethylindolin-2-ylidene] penta-I,3-dienyl)-I-ethyl-3,3-dimethyl-3H-indolium chloride; DAPI, 4',6-diamidino-2-phenylindole. 
A

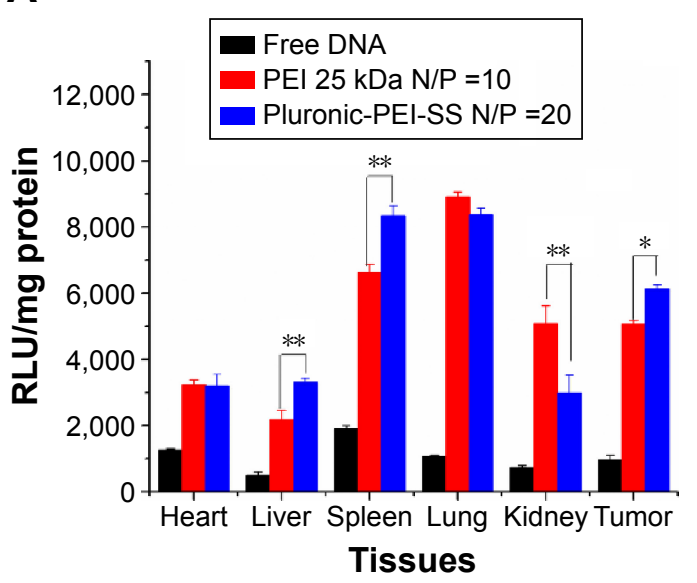

B

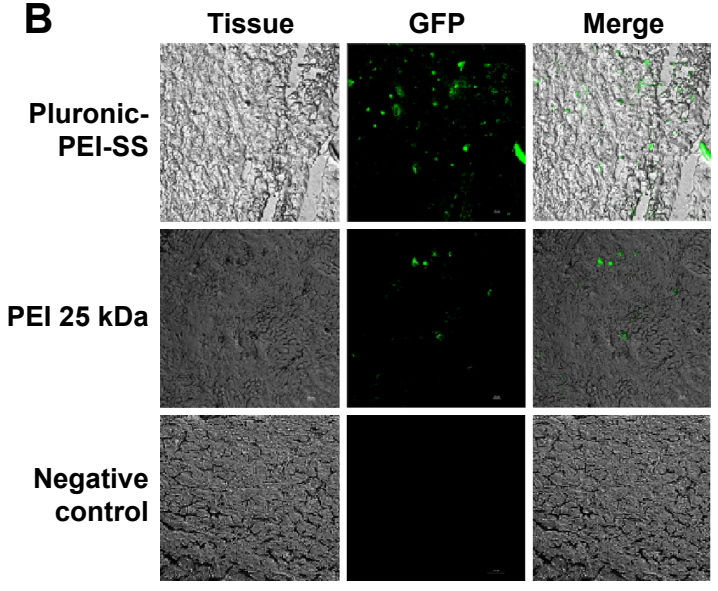

Figure 10 In vivo gene transfection evaluation.

Notes: $(\mathbf{A})$ Tissue distribution of luciferase expression following iv administration of pGL4-luc formulated Pluronic-PEI-SS or PEI $25 \mathrm{kDa}$ by injection into the tail vein ( $50 \mu \mathrm{g}$ of DNA per mouse). Tissues and tumors were collected 24 hours following injection. Data are presented as mean $\pm S D(n=3$, $* P<0.05$; $* * P<0.0 I)$. (B) The transfection image of GFP-expressing collected tumor using Pluronic-PEI-SS and PEI $25 \mathrm{kDa}$ as gene delivery vehicles.

Abbreviations: GFP, green fluorescent protein; PEI, polyethyleneimine; PEI-SS, disulfide-linked PEI; N/P, nitrogen to phosphate; iv, intravenous; RLU, relative light unit.

achieved $\sim 3,600,8,200$, and 6,500 RLU/mg, respectively, in the organs, and higher level of luciferase activity was observed in these tissues. Especially, the transfection efficiency of Pluronic-PEI-SS/DNA in tumor was statistically significantly higher than that of PEI $25 \mathrm{kDa} / \mathrm{DNA}$. In liver and spleen with Pluronic-PEI-SS/DNA, the transfection efficiency was statistically significantly higher than that of PEI $25 \mathrm{kDa} / \mathrm{DNA}$ complexes. The result obtained from tumor distribution also demonstrated a higher transfection efficiency of Pluronic-PEI-SS/DNA nanocomplex than that of PEI/DNA complex $(P<0.05)$.

Furthermore, the EGFP DNA transfected cells incubated with the copolymer Pluronic-PEI-SS showed more bright green fluorescent spots than the control, as observed by fluorescence microscopy (Figure 10B). The higher in vivo transfection efficiency of the Pluronic-PEI-SS complexes can be attributed to the partial neutralization of the positive charge by Pluronic, the degradable properties of disulfide bonds, and the weak interaction between the degraded PEI short chains and DNA to enhance the release of DNA.

\section{Conclusion}

This study showed that the novel bioreducible PluronicPEI-SS copolymer formed by cross-linking disulfidecontaining PEI (600 kDa) with Pluronic was successfully synthetized. The copolymer displayed a high affinity for DNA with a low surface charge density and suitable size, protected DNA from DNase I digestion, and also exhibited a bioreducible property in the presence of reducing agent DTT. The complex Pluronic-PEI-SS/DNA could significantly improve the in vitro transfection efficiency with low cytotoxicity, in comparison to Pluronic-PEI (25 $\mathrm{kDa})$, PEI-SS, and PEI $25 \mathrm{kDa}$. Furthermore, the in vivo transfection study demonstrated that Pluronic-PEI-SS/DNA complexes induced a significantly high enrichment in the tumor and exhibited higher efficiency than the commercial PEI/DNA complex. The resulting bioreducible nanocomplex could be used as a potential gene delivery system in future.

\section{Acknowledgments}

We acknowledge the support from the National Natural Science Foundation of China $(21104029,21074049)$ and the Gansu Province Science Foundation for Youth (1107RJYA038). We also acknowledge the support by the grants from the Fundamental Research Funds for the Central Universities (1zujbky-2015-22) and Innovation and Entrepreneurship Program of Lanzhou University (20151073001320). We thank Prof Youqing Shen (Zhejiang University) for his help in gene delivery vectors and the animal experiment conditions.

\section{Disclosure}

The authors report no conflicts of interest in this work.

\section{References}

1. Cavazzana-Calvo M, Hacein-Bey S, Basile CD, et al. Gene therapy of human severe combined immunodeficiency (SCID)-X1 disease. Science. 2000;288(5466):669-672.

2. Yang ZR, Wang HF, Zhao J, et al. Recent developments in the use of adenoviruses and immunotoxins in cancer gene therapy. Cancer Gene Ther. 2007;14(7):599-615.

3. Luo D, Saltzman WM. Synthetic DNA delivery systems. Nat Biotechnol. 2000;18(1):33-37.

4. Behr JP. Synthetic gene transfer vectors II: back to the future. Acc Chem Res. 2012;45(7):980-984. 
5. Atmaja B, Lui BH, Hu YH, Beck SE, Frank CW, Cochran JR. Targeting of cancer cells using quantum dot-polypeptide hybrid assemblies that function as molecular imaging agents and carrier systems. Adv Funct Mater. 2010;20(23):4091-4097.

6. Goyal R, Tripathi SK, Tyagi S, et al. Gellan gum blended PEI nanocomposites as gene delivery agents: evidences from in vitro and in vivo studies. Eur J Pharm Biopharm. 2011;79(1):3-14.

7. Barua S, Joshi A, Banerjee A, et al. Parallel synthesis and screening of polymers for nonviral gene delivery. Mol Pharm. 2009;6(1):86-97.

8. Cemazar M, Sersa G, Wilson J, et al. Effective gene transfer to solid tumors using different nonviral gene delivery techniques: electroporation, liposomes, and integrin-targeted vector. Cancer Gene Ther. 2002; 9(4):399-406

9. Bansal R, Singh AK, Gandhi RP, Pant AB, Kumar P, Gupta KC. Galactomannan-PEI based non-viral vectors for targeted delivery of plasmid to macrophages and hepatocytes. Eur J Pharm Biopharm. 2014; 87(3):461-471.

10. Kuo JS. Effect of pluronic-block copolymers on the reduction of serum-mediated inhibition of gene transfer of polyethyleniimine-DNA complexes. Biotechnol Appl Biochem. 2003;37:267-271.

11. Yang Z, Sahay G, Sriadibhatla S, Kabanov AV. Amphiphilic block copolymers enhance cellular uptake and nuclear entry of polyplexdelivered DNA. Bioconjuate Chem. 2008;19:1987-1994.

12. Batrakova EV, Miller DW, Li S, Alakhov VY, Kabanov AV, Elmquist WF. Pluronic P85 enhances the delivery of digoxin to the brain: in vitro and in vivo studies. J Pharmacol Exp Ther. 2001;296(2):551-557.

13. Lemieux P, Guerin N, Paradis G, et al. A combination of poloxamers increases gene expression of plasmid DNA in skeletal muscle. Gene Ther. 2000;7(11):986-991.

14. Pitard B, Bello-Roufai M, Lambert O, et al. Negatively charged selfassembling DNA/poloxamine nanospheres for in vivo gene transfer. Nucleic Acids Res. 2004;32(20):e159.
15. Gebgart LC, Sriadibhatla S, Vinogradov S, Lemieux P, Alakhov VY, Kabanov AV. Design and formulatin of polyplexes based on pluronicpolyethyleneimine conjugates for gene transfer. Bioconjugate Chem. 2002;13:937-944.

16. Richard P, Bossard F, Desigaux L, Lanctin C, Bello-Roufai M, Pitard B. Amphiphilic block copolymers promote gene delivery in vivo to pathological skeletal muscles. Hum Gene Ther. 2005;16(11):1318-1324.

17. Richard P, Pollard H, Lanctin C, et al. Inducible production of erythropoietin using intramuscular injection of block copolymer/DNA formulation. J Gene Med. 2005;7(1):80-86.

18. Yang ZH, Zhu J, Sriadibhatla S, Gebhart C, Alakhov V, Kabanov A. Promoter- and strain-selective enhancement of gene expression in a mouse skeletal muscle by a polymer excipient Pluronic P85. J Control Rel. 2005; 108(2-3):496-512.

19. Liang WQ, Gong HY, Yin DF, Lu SY, Fu Q. High-molecular-weight polyethyleneimine conjuncted pluronic for gene transfer agents. Chem Pharm Bull. 2011;59(9):1094-1101.

20. He YY, Cheng G, Xie L, Nie Y, He B, Gu ZW. Polyethyleneimine/DNA polyplexes with reduction-sensitive hyaluronic acid derivatives shielding for targeted gene delivery. Biomaterials. 2013;34(4):1235-1245.

21. Read ML, Logan A, Seymour LW. Barriers to gene delivery using synthetic vectors. Adv Genet. 2005;53:19-46.

22. Nguyen HK, Lemieux P, Vinogradov SV, et al. Evaluation of polyetherpolyethyleneimine graft copolymers as gene transfer agents. Gene Ther. 2000;7(2):126-138.

23. Breunig M, Lungwitz U, Liebl R, Goepferich A. Breaking up the correlation between efficacy and toxicity for nonviral gene delivery. Proc Natl Acad Sci U S A. 2007;104(36):14454-14459.

24. Read ML, Singh S, Ahmed Z, et al. A versatile reducible polycationbased system for efficient delivery of a broad range of nucleic acids. Nucleic Acids Res. 2005;33(9):e86.
International Journal of Nanomedicine

\section{Publish your work in this journal}

The International Journal of Nanomedicine is an international, peerreviewed journal focusing on the application of nanotechnology in diagnostics, therapeutics, and drug delivery systems throughout the biomedical field. This journal is indexed on PubMed Central, MedLine, CAS, SciSearch ${ }^{\circledR}$, Current Contents ${ }^{\circledR} /$ Clinical Medicine,

\section{Dovepress}

Journal Citation Reports/Science Edition, EMBase, Scopus and the Elsevier Bibliographic databases. The manuscript management system is completely online and includes a very quick and fair peer-review system, which is all easy to use. Visit http://www.dovepress.com/ testimonials.php to read real quotes from published authors. 